\title{
Encouraging Better Hand Drying Hygiene
}

\author{
Sally Jo Cunningham \\ Computer Science Dept \\ University of Waikato \\ Hamilton, New Zealand \\ +6478384402 \\ sallyjo@cs.waikato.ac.nz
}

\author{
Andrew Will \\ Computer Science Dept \\ University of Waikato \\ Hamilton, New Zealand \\ +6478384021 \\ akw2@cs.waikato.ac.nz
}

\begin{abstract}
Electric hand driers have the potential to improve sanitation when using public toilets; if used properly, electric driers can dry hands more thoroughly than towels, and users do not come into physical contact with potentially contaminated objects. But electric driers are frequently used for just a few seconds - and so the potential advantage is lost. This paper describes the prototyping and evaluation of a system intended to encourage longer hand drying times in public toilets. The challenges are: to develop hygienic interfaces for use in toilet areas; to design simple to use software that is engaging enough to be used several times a day; and to conduct usability and system acceptance tests in an environment in which users are highly sensitive about privacy issues.
\end{abstract}

\section{Categories and Subject Descriptors}

D.3.3 [Programming Languages]: Language Constructs and Features

\section{General Terms}

Design, Human Factors

\section{Keywords}

Hygienic interfaces, public restrooms, entertainment software, privacy issues

\section{INTRODUCTION}

Electric hand driers have largely replaced paper towels in public toilets worldwide. The impetus for the switch has been justified by energy savings (it takes less energy to produce a hot air exhaust than to manufacture, transport, and dispose of towels) and by the potential for better hygiene. The latter point, the sanitation aspects of hand drier use, has been a subject of debate.

Folk theory holds it that warm air hand driers are less sterile than paper towels. But drying hands with hand driers is significantly likely to generate airborne microorganisms than drying with paper towels - in trials conducted in public restrooms, reductions of 30 to $75 \%$ were recorded when moving from paper towels to air

Permission to make digital or hard copies of all or part of this work for personal or classroom use is granted without fee provided that copies are not made or distributed for profit or commercial advantage, and that copies bear this notice and the full citation on the first page. To copy otherwise, to republish, to post on servers or to redistribute to lists, requires prior specific permission and/or a fee. CHINZ 2008, July 2, 2008, Wellington, New Zealand (c) 2008 ACM 978-1-60558-467-6/07/0008...\$5.00 driers [12]. The outer casing of the hand drier and its air inlet/output vents contained about the same as, or smaller, levels of microorganisms as other restroom surfaces.

But what about the cleanliness of the restroom user's hands - does the air drier offer similar improvements in hygiene to the individual as it does to the restroom environment? In laboratory tests [12], the answer is an unequivocal 'yes'-so long as the hands are dried for the recommended time for that particular drier model. This recommended time is typically $30-45$ seconds, to achieve $95 \%$ dryness. Unfortunately, in practice few people use the driers as recommended. A study of drier use in natural conditions concluded that, "the majority of people are too impatient to use hot air driers for long enough to ensure adequate dryness" [4] - averaging roughly half the recommended time. Roughly $40 \%$ of the users were observed to finish drying their hands by wiping their hands on their clothes, hair, or body, practices which can easily spread microorganisms when the individual leaves the restroom.

The Knights, et al study [4] does not probe further into the reasons why people do not use the air driers as intended, beyond the conjecture that users are simply 'too impatient'. This is undoubtedly sometimes the case, but from personal experience we believe that there are other significant factors that influence the time people spend drying their hands. Forty-five seconds is a long time to stand facing a blank wall with one's hands under warm air; we believe it likely that many users become bored and so abbreviate the drying process. Further, when others are standing in line to use the drier, water dribbling down to their elbows and dripping onto the floor, it is socially awkward to the point of rudeness to continue drying, and so the user may quit after only a few seconds.

In this paper we describe two prototype software applications intended to encourage longer use of air driers by providing an alternative to staring at the restroom walls while they use the driers. Sheer impatience is difficult to overcome, but if users are simply bored then an interesting activity could encourage them to dry for longer periods. If social pressure to relinquish the drier is a factor, then perhaps being engaged in an additional activity to drying could help in resisting that pressure.

This paper is organized as follows: in Section 2, we review related research on computing applications in public and private washrooms. Section 3 describes two software applications intended for use while using a warm air drier, and discusses the alternatives for hygienic input devices for use in a public restroom. Section 4 presents the results of a six-week trial in a university men's room, and in Section 5 we give our conclusions. 


\section{RELATED WORK}

Early research focusing on applications in public restrooms includes a mathematical model of toilet paper use in stalls with two rolls of paper [5]. While the model was never implemented, this investigation included a categorization of restroom users by their preference in paper roll choice (the big-choosers and littlechoosers, who select the roll that is the most or least full, respectively); this deep understanding of paper selection behavior can be inferred to come from informal observation of paper use in a Stanford University men's restroom.

Behavior in public and private toilet areas is tangentially examined in studies of mobile phone use [1] and the acceptability of interruptions by remote communication devices [11]. Both studies find that people are generally reluctant to engage in conversation / communication while in a restroom; this indicates that a system intended for that environment should be a singleuser application.

More detailed studies of behavior in toilets are rare; we were only able to identify two, one of personal bathroom facilities in the Netherlands [6], and a second of public toilet use in Hong Kong [9]. Both focus on developing improvements to existing physical toilet area amenities, while maintaining good hygiene. The latter investigation met with limited success in applying standard HCI investigatory techniques to the public toilet environment:

Direct interviews with users are also difficult, since in general people are not willing to respond to questions inside toilets. Our research team also faced great difficulty

taking photos inside toilets. [9]

The Netherlands-based study opted for a small, qualitative investigation based around Cultural Probes [6]. This approach allowed the researchers to gradually gain the trust of their participants, and gave the participants a high level of control over the personal information communicated-but at the cost to the research of restricting the study to a handful of households. A large-scale study simply cannot involve direct contact with toilet users, or even overt monitoring by video camera or direct observation - that simply is not acceptable in restroom/toilet environments. Instead, broader studies must utilize anonymous activity measures - detecting toilet flushes, water tap usage, and so forth [2].

While no previous systems were found that specifically focus on augmenting the hand drier use experience, three earlier applications have been proposed for use on the toilet itself: You're in Control [7], the Toilet Entertainment System [10], and iFlush [3]. The first is a urinal augmented with a software game; the game is played by directing streams of urine at sensors located inside the urinal. While the main purpose of You're in Control is entertainment, the developers speculate that its usage may result in cleaner restrooms (by encouraging better aim in urinal use). We drew upon the playful nature of this system in designing our first application (Section 3.2). The Toilet Entertainment System (TES) uses motion-sensing tiles to allow the user to select a news category; the latest stories in that category are then printed on toilet paper, giving the TES user something to read while using the toilet. We took on board the importance of improving sanitation by providing hands-free interaction (Section 3.1), and the idea of supporting people in reading in the restroom (Section 3.3). Both You're in Control and TES were prototyped, but not tested in restrooms. iFlush requires users to verbally 'offload information', which is then printed on toilet paper for immediate use. This is a 'conceptual critical design' rather than an implemented system, designed to 'demonstrate criticism towards information overload in today's society' [3]. We will come back to this point in the conclusion (Section 5); here, we note that people are likely to resist using voice input systems in a public toilet.

\section{SYSTEM DESIGN AND IMPLEMENTATION}

In this section, we describe the factors involved in designing a suitable input device (Section 3.1), the two software applications developed for intended use while drying one's hands (Sections 3.2 and 3.4), and mechanism used to detect the activation / deactivation of a hand drier (Section 3.5), and the creation of the physical input device (Section 3.6).

\subsection{User Input}

It quickly became clear that the interface for the system must operate hands-free. Sanitation demands that users be able to operate the software without touching any physical objects - and public toilet users often go to great lengths to avoid touching fixtures and door handles [9]. A gesture-based interface would be infeasible, as the user must keep both hands within the exhaust area of the drier - a tiny space, in which it is likely that one hand will occlude gestures made with the other. Hand gestures also usually require practice before they can be accurately recognized, but the short time in which the software will be used (up to 45 seconds) demands a learning time of at most a few seconds. The noise of the hand driers renders a voice-operated interface technically infeasible, and from a context-of-use standpoint people are likely to feel awkward dictating commands to a hand drier in a public space.

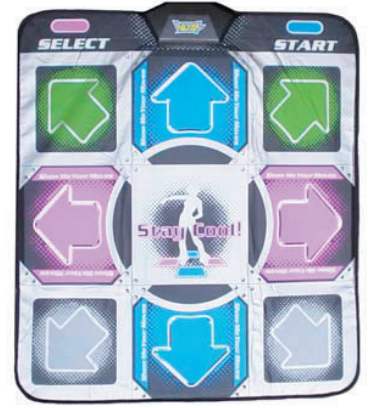

Figure 1a. The Playstation2 Dance Mat.

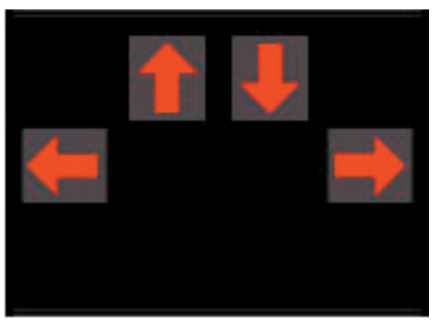

Figure 1b. Layout of the mat used in this study.

This process of elimination suggested a foot-operated input device. Feet are encased in shoes in public areas, so users are unlikely to have hygiene concerns about touching the physical 
input device ${ }^{1}$. The Playstation2 Dance Mat (Figure 1a) suggested itself as a potential input device. The arrows on the mat correspond to cursor movements or to similar icons in the interface; for example, stepping on the 'right' arrow will navigate a screen object to the right. But someone operating a hand drier needs a larger space to stand in than the inner tile of the Dance Mat, and should have a clear path to step up to the hand drier. The layout used in this project addresses these issues by laying out the foot controls in the pattern presented in Figure $1 \mathrm{~b}$.

\subsection{A Fishy Game}

Time is the most significant constraint in the design of a game to be used when drying one's hands. The optimal time to use a public hand drier is $30-45$ seconds; in that brief period the user must be able to learn the rules of the game and play a game to its conclusion. This argues for simple gameplay-a limited number of controls/commands that can be easily listed on an introduction window, a goal that is quickly grasped, and straightforward strategies to achieve that goal. The game should also be similar to existing games, again so that its purpose and play can be rapidly understood.

But an overly simple game will be played once or twice, and many public toilets - those in workplaces, for example-are potentially visited by the same individuals several times a day, over extended time periods. We need a mechanism for encouraging users to play the game even after they feel that they have mastered it. One standard technique for encouraging repeated game play is to tap into the native human competitive spirit by posting individuals' high scores-noting that one's score has been knocked off the High Scores list is a known motivator to play a game again. And, of course, the game would have to be periodically replaced by another, to maintain interest through novelty.

The lighting in public toilets is generally harsh; fluorescent lights in particular tend to wash out colors. Coupled with the need to catch a potential user's attention within a few seconds of using the hand drier, these considerations suggest bright, highly saturated graphics, with high contrast between the different screen elements. Hand driers are loud, and the toilet environment is generally noisy - toilets flushing, water taps running - indicating that the gameplay interest should focus tightly on the visual, and could not rely on the clear audibility of sound and music to add to the playing experience.

The prototype game evaluated, 'A Fishy Game', was implemented in Macromedia Shockwave - chosen for its support of high quality graphics as well as fast development of interactive software. The initial screen, Figure 2a, provides an overview of the game. This screen is the default display, and is visible until the hand drier is activated. The goal of the Fishy Game is to earn points by blowing up fish, achieved by detonating bombs when fish swim near them. Different types of fish attract different points rewards when they are killed. Fish swim around the visible ocean bed at random. Each bomb is matched to one of the four footpad controls, and the user taps a footpad controls to select a particular

${ }^{1}$ Indeed, Siu [9] reports that in Hong Kong, people worried about the possible transmission of infectious diseases often use their feet to flush the commodes, to avoid touching the toilet handles with their hands.

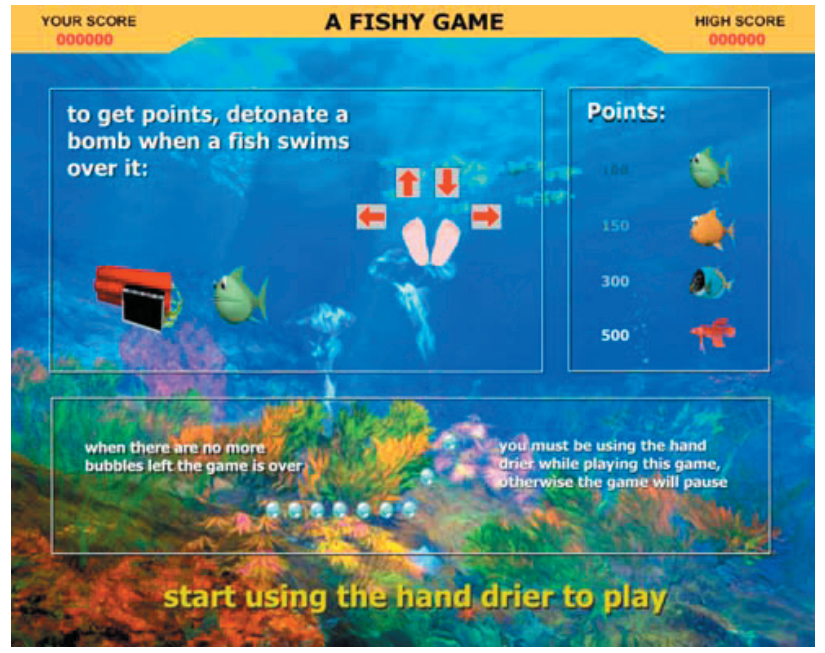

Figure 2a. Initial game screen.

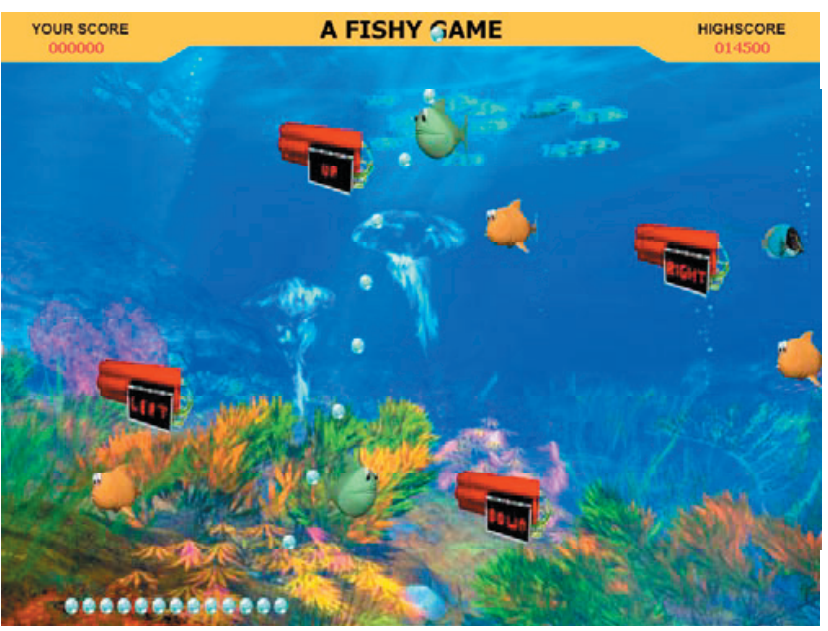

Figure 2b. Playing The Fishy Game.

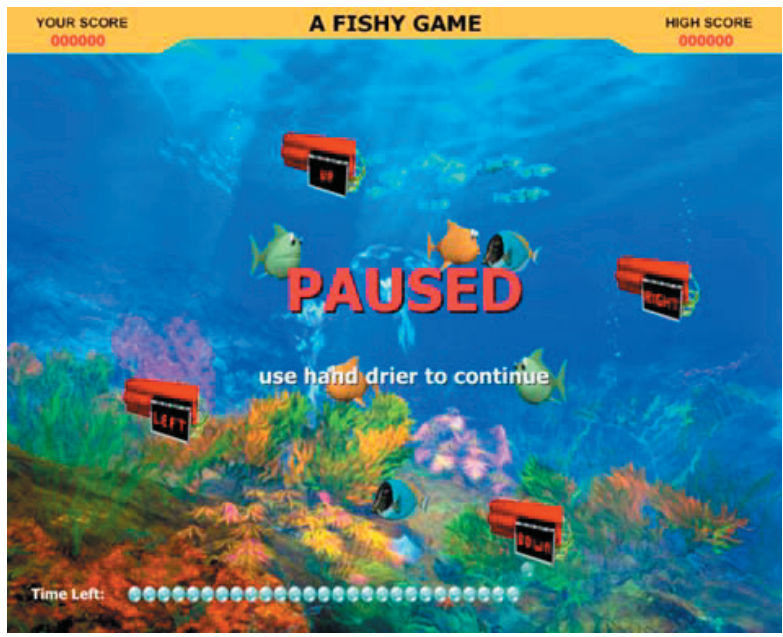

Figure 2c. The Fishy Game on pause. 
bomb and detonate it. One or two bomb detonations should be sufficient to gain a sense of how close a fish has to be to the bomb, to be killed.

A new game begins when the hand drier is activated (Figure $2 b$ ). The line of bubbles at the bottom of the screen provide a simple indicator of time remaining: bubbles float away one by one, and when the final bubble vanishes then the game is over and the final score is displayed. The bubble line can be lengthened or shortened to match the recommended use time for specific hand driers; when testing the prototype, the optimal drying time for the installed hand driers was 45 seconds.

The game can only be played while the hand drier is in use. When the hand drier stops, the game is paused for a few seconds (Figure $2 c)$. The user is encouraged to re-start the hand drier to continue the game. If the user does not re-start the drier, then the game is ended and the final score is displayed.

Note that no player identifiers are associated with the current game score and high score. Adding functionality to include names would have greatly complicated the interface, and we were unsure whether users would wish to leave names-even a pseudonym - in a public restroom.

\subsection{Article Viewer}

Internationally, the walls in public toilets are used to display reading matter such as public health notices, advertisements for upcoming events [8], or reading matter likely to appeal to the interests of the users ${ }^{2}$. Users of public toilets are, briefly, a captive audience, in need of something to occupy them as they wait in line, dry their hands, and so forth. Social conventions may inhibit conversations in public toilets (or sometimes even prohibit acknowledging the presence of other users); in these circumstances reading is ideal to pass the time. In private homes books and magazines may be set out for reading in the toilet [Lucerno], but it is not socially acceptable to bring books into public restrooms $[10]^{3}$. Nor would it be hygienic to maintain a stock of physical books or magazines in a public facility, since they would have to be handled to be read. Sanitary concerns appear to be the motivation for putting up reading matter as posters in public toilets, rather than leaving out leaflets or magazines.

Our second application, then, displays brief, quirky news stories. The look and feel of this interface is adapted from the Playstation 2 game 'Singstar', which has a scrolling selection interface for choosing music videos. Once the hand drier is activated, the footpads can be used to select a story (Figure 3a). The text of the story is displayed (Figure $3 b$ ), and the footpads can be used to return to the main menu or scroll through the story (if it is longer

${ }^{2}$ In New Zealand, for example, the second author has noticed that the walls and stalls of men's toilets in pubs frequently feature recent newspaper articles about sporting events or new 'toys for the boys' technology. The first author confirms that women's toilets, however, do not have posted reading matter.

${ }^{3}$ Readers will perhaps remember the classic Seinfeld episode in which George violates this convention by taking a book into a bookstore's restroom, and then is forced to purchase it because it is now a 'bathroom book' that no one else will be willing to buy or even touch. than a single screen). The criteria for selecting news articles were relative brevity (so that a moderately fast reader could get through two in 45 seconds), a humorous or unusual topic, and low probability of offensiveness (for example, no political or religious stories were included). Since it is easy to inadvertently deactivate the hand drying by moving one's hands outside the infra-red detector's range, a 'pause' screen appears for a few seconds after the drier stops, to allow the user to continue reading the article by starting the drier up again.

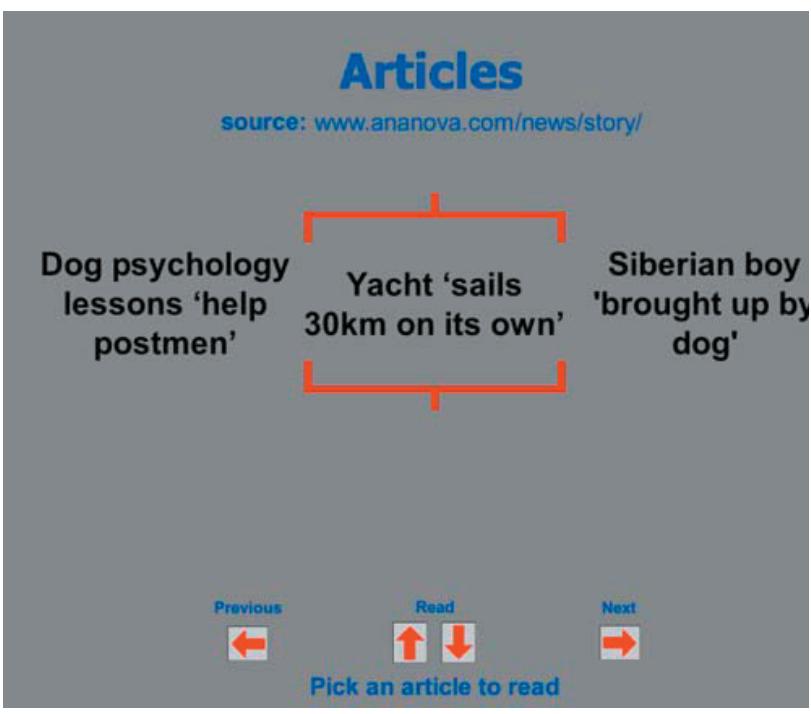

Figure 3a. Initial screen of the news article viewer.

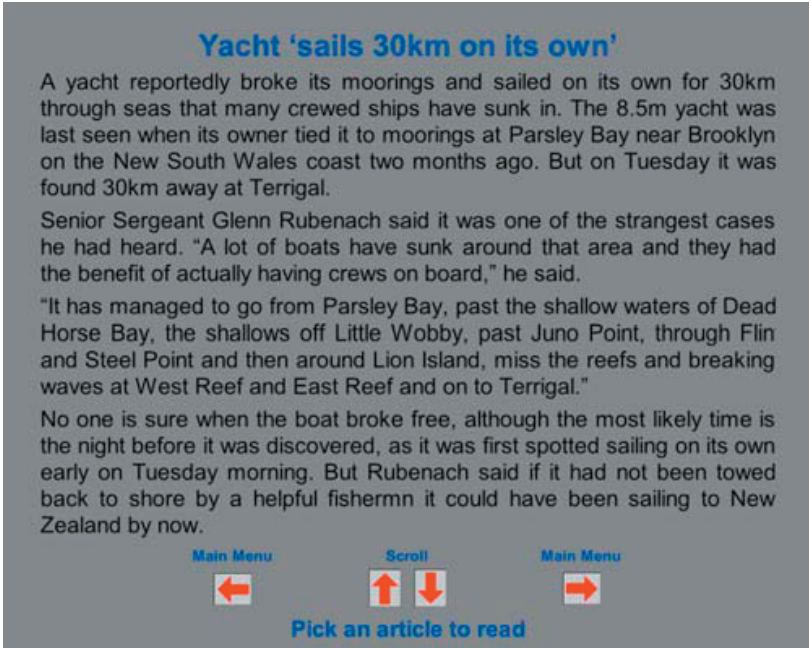

Figure 3b. A sample article.

\subsection{Recognizing Hand Drier Use}

To encourage use of hand driers for the recommended times, we developed software that can be used only when the drier is operating. Ideally, the hand drier internal controls would be tapped to identify when the drier is turned on or off, but we could not interfere directly with the drier's functioning. This forced us to develop a separate system for detecting when the drier was in use. A second motion detector attached to the hand drier was 
considered, but there was no space for an additional detector. A digital video camera or webcam could easily be set up to detect hand drier use, but video monitoring in a bathroom is viewed as an unacceptable violation of privacy [2]. Infrared proximity sensors were tested but found to be too susceptible to background movement (for example, other people walking past). Heat sensors (set in the path of the drier exhaust) react too slowly to changes in temperature to accurately capture the activation/deactivation of the drier.

Only one feasible option remained: audio detection. Audio monitoring is less invasive than video monitoring [2], particularly if the audio device detects sound but does not store it. Given that hand driers are loud and cut off and on abruptly, there is a clear sound threshold indicating when the drier is in use. We positioned a $30 \mathrm{~mm}$ piezoelectric transducer near the hand drier, and connected the transducer to a computer's microphone port. A simple program was developed to check the port every 10 milliseconds, to detect sounds above a given threshold (developed by experimentation with a specific hand drier) - indicating that the drier is being used.

\subsection{Building the foot controlled input device}

A foot-based input device has to be built to take a bit of punishment; the controls may be stepped on with some force, and possibly with the entire weight of the user. Our implemented device had to be sturdy and reliable enough to allow us to evaluate the complete system under real conditions - a university toilet (Section 4).

The four individual foot controls ('footpads') were each constructed on a breadboard. Three switches were inserted into each breadboard to capture a foot press - so that the user could step on any part of the footpad area, and at least one switch would be activated. The switches were connected in parallel, so that when any one of the switches is pressed, a signal is sent (Figure 4a). A small metal plate of the same size as the breadboard was then mounted on top of the breadboard, to act as a pedal. To prevent the plate from bending or breaking, rubber was used to cushion the plate. The rubber acts as a support if the user presses the footpad at a sharp angle. The plates were then glued to the switches (Figure $4 b$ ).

Next, a household 'welcome' mat was used as a base for the four footpads. Small recesses were cut into the mat, slightly larger than a breadboard, so that each footpad would rest in a recess and jut out several millimeters (Figure 4c). The connector wires from all four footpads were fed out the center top of the mat. The mat was then covered with rubber butynol sheeting and glued down with butynol adhesive, to act as a water resistant skin to the mat. This is important to reliable functioning, to prevent any water dripping from the wet hands from seeping into the breadboards. Finally, the footpads were marked with arrow icons.

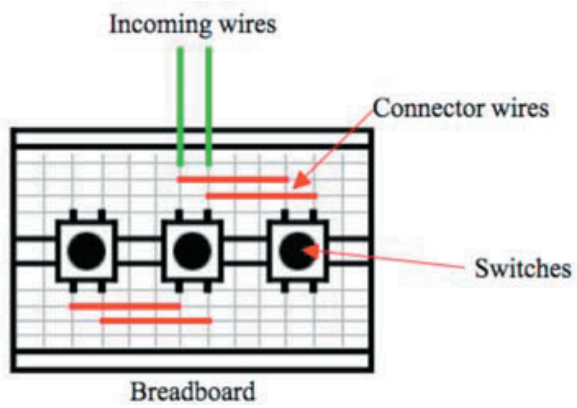

Figure 4a. Birds-eye view of a footpad breadboard.

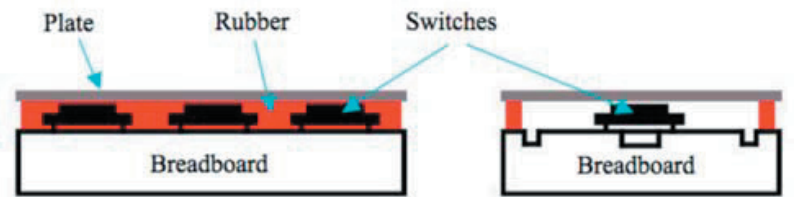

Figure $4 \mathrm{~b}$. Side-on view of the breadboard (left) and end-on view (right), with the plate on top (grey).

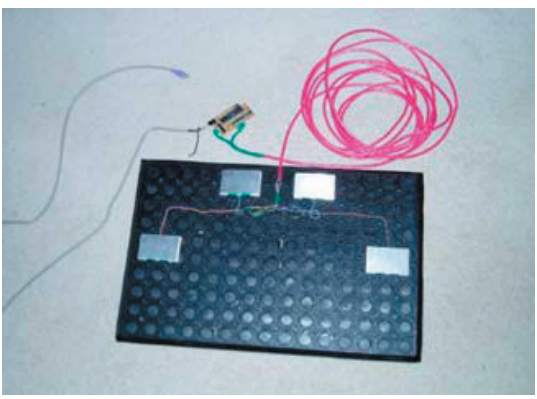

Figure 4c. The mat, prior to gluing down the rubber sheeting.

\section{EVALUATION}

The effectiveness of The Fishy Game and the Article Viewer in encouraging hand drying could only be evaluated by testing in a real public toilet. We chose a men's room at Waikato University, in a building containing mainly staff offices and computer labs. While a restroom in a teaching building would have a higher number of users, the office building provided greater security for the equipment, and the software could be monitored more easily to ensure that it was functioning correctly.

Consent was obtained from the University's Ethics Committee to install and evaluate an interactive system attached to the hand drier in the men's room. During all of the trials, a sign was posted outside on the door stating: "The duty cycle of the hand drier is being monitored". Every floor in the building has a men's room, so people who did not wish to participate in the experiment were not inconvenienced.

First, control data was obtained on hand drier usage. The Piezoelectric transducer was discreetly attached to the wall near the drier, and connected to a computer hidden above the ceiling. A simple logging application was developed to record timestamps for each activation / deactivation of the hand drier. Two weeks of control data were obtained. 
Next, the full physical system was installed (Figure 5). A monitor was placed beside the drier on a specially constructed cabinet, angled so that the screen would be clearly viewable by anyone using the hand drier. The Fishy Game was installed and hand drier usage captured for two weeks, and then the Article Viewer was installed and its usage monitored for a further two weeks. All three trial periods - control, The Fishy Game, the Article Viewer-were held during teaching term, so the restroom was expected to receive roughly consistent amounts of use during each trial. Another lecturer encouraged students to test the system during the trial of The Article Viewer, however, so there was a significant increase of users during that trial.

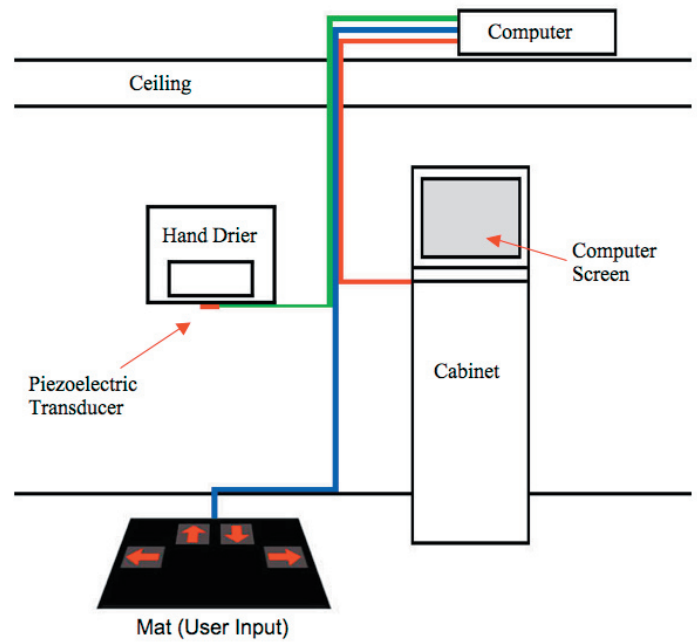

Figure 5. The experimental setup as installed in a public men's restroom.

Table 1 presents the results of the trials. Both The Fishy Game and the Article Viewer significantly increased the time that users spent to dry their hands (although the times for the Article Viewer trial must be viewed with caution, given that some users were students experimenting with the system). For both, the increases over the control were significant to the $99 \%$ confidence level. Examination of plotted drier usage times reveals that the middle $80 \%$ of usage in the control lay in range 4.12 to 29.38 seconds; for the Game, in the range 4.04 to 34.4 seconds; and for the Article Viewer, from 3.3 to 37.5 seconds.

As noted in Section 2, it is difficult to obtain direct user feedback about restroom-based applications. It was not possible to gain ethics approval to conduct interviews with users of either The Fishy Game or the Article Viewer, and so evidence for the usability and acceptability of either application must be inferred from the hand drier usage logs (we did not obtain ethics consent to store and analyze logs from the software applications themselves). We did, however, have one unsolicited email from an enthusiastic user of The Fishy Game:

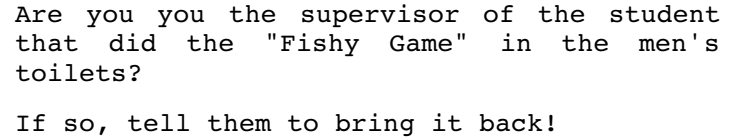

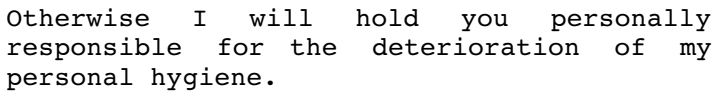

Table 1. Experimental results.

\begin{tabular}{|l|c|c|c|}
\hline & Control & Game & Article \\
\hline $\begin{array}{l}\text { Length of } \\
\text { Experiment }\end{array}$ & 2 weeks & 2 weeks & 2 weeks \\
\hline $\begin{array}{l}\text { Number of } \\
\text { Samples }\end{array}$ & 263 & 286 & 465 \\
\hline Mean (seconds) & 15.92 & 17.97 & 18.22 \\
\hline Median & 14.7 & 14.95 & 16.3 \\
\hline Mode & 15.7 & 19 & 8.89 \\
\hline Minimum & 1.49 & 1.3 & 1.3 \\
\hline Maximum & 50.4 & 76.1 & 58.2 \\
\hline Std Dev _(Between & - & 7.12667 E-08 & 0.00252267 \\
\hline $\begin{array}{l}\text { F-Test (B) } \\
\text { Control \&_ }\end{array}$ & & 12.27 & 14.48 \\
\hline
\end{tabular}

\section{CONCLUSIONS}

We have described two applications intended to encourage longer hand drier use than typically occurs in public restrooms. One contribution of this research is the testing of our prototypes in a real environment, over a reasonable period of time; earlier restroom-based applications underwent laboratory testing only or remained in the conceptual design stage (Section 2). Our evaluations confirmed earlier experience that evaluating restroom applications is an ethics and privacy minefield. The most acceptable way to gain information about restroom behaviormonitoring equipment use in that environment, such as toilet flushes, hand drier activations, and so forth-captures only the most basic data about the restroom experience. We discovered that even the gathering of that sort of data can be contentious; our original plan to use a microphone (unconnected to a recording device) to capture drier activation/deactivation was not acceptable to local users, so instead we used the piezoelectric transducerwhich had exactly the same function, but has a less threatening appearance.

The two applications were both moderately successful in meeting their intended purpose: hand drier usage times increased significantly when they were installed, although the mean/mode usage times did not reach the 30 second threshold suggested by the manufacturer. It is likely that further modifications of the game and article viewing interface could make their use more enjoyable, and further extend the hand drying time. We note that both applications would require frequent updates to maintain user interest: the game would need to be changed possibly once or twice a month, and the news articles would need to be refreshed much more often. The Article Viewer has the advantage in that respect, as it would be straightforward to update automatically from a news website. 
We also contribute a novel input mechanism for environments in which hygiene is a concern: the foot-operated mat. This device is easy to clean, and leaves the user's hands free for other actions (eg, using the warm air drier). The mat does have to be of durable construction, however, to withstand forceful presses.

A deeper question has been raised by earlier work in this area, notably TES [10] and iFlush [3]: should there be limits to ubiquitous access to computers and information? These researchers note that the toilet is 'the last frontier for nonaugmented rooms' [3], 'a place for contemplation and reflection' [10] in which people resist-sometimes vigorously-remote communication or other attempts to make the time spent there more 'productive' [11]. We share the concerns of [3]:

Instead of focusing on augmenting every inch of the world, maybe HCI should direct some of its resources toward ... providing physical and digital spaces for users to reflect and offload informational burdens.

Given the enthusiasm (in the research and commercial spheres) for pervasive and ubiquitous computing, it seems likely that this last frontier for HCI will soon disappear. At the very least, we feel that the use of any restroom-related computing applications should be made optional, so that the strong-minded user can retain this last sheltered zone free from the information deluge; at best, we hope that fielded applications not involve direct communication with other people, so that some fragments of solitary time are still available to us.

\section{REFERENCES}

[1] Arminen, I. Social functions of location in mobile telephony. 2006. Personal and Ubiquitous Computing, 10, 319-323.

[2] Chen, J., Kam, A.H., Zhang, J., Liu, N., and Shue, L. 2005. Bathroom activity monitoring based on sound. Proceedings of Pervasive Computing 2005, Munich (Germany), 47-61.

[3] Dalsgaard, P., Eriksson, E., and Hansen, L.K. 2005. Rethinking information handling: Designing for information offload. Proceedings of AARHUS 2005, Arhus (Denmark), 161-164.
[4] Knights, B., Evans, C., Barrass, S., and McHardy, B. 1993. Hand Drying: An assessment of efficiency and hygiene of different methods. The Association of Soft Tissue Paper Manufacturing, 3 - 15 .

[5] Knuth, Donald E. 1984. The Toilet Paper Problem. The American Mathematical Monthly, 91(8), 465-470.

[6] Lucero, A., Lashina, T., Diederiks, El, and Mattelmaki, T. 2007. How probes inform and influence the design process. Proceedings of Designing Pleasurable Products and Interfaces, Helsinki (Finland), 377-391.

[7] Maynes-Aminzade, D., and Raffle, H.S. 2003. You're in Control: A urinary user interface. Proceedings of CHI 2003 (Ft Lauderdale, FL, USA). ACM Press, New York, 986-987.

[8] Namakura, M.A. 2004. Creating a new channel for campus communication. Proceedings of SIGUCCS '04 (Baltimore, MD, USA). ACM Press, New York, 56-59.

[9] Siu, K.W.M. 2004. Human-product-interface design of facilities in public toilets. Presented at The 2004 World Toilet Summit, Hong Kong. Available at: http://www.worldtoilet.org/articles/wts2004/Human-ProductInterface-Design-Of-Facilities-In-Public-Toilets.pdf

[10] Stenberg, P., and Thoresson, J. 2003. The Toilet Entertainment System. Proceedings of CHI $2003(\mathrm{Ft}$ Lauderdale, FL, USA). ACM Press, New York, 1000-1001.

[11] Takamae, Y., Chaki, S., Ohno, T., Yoda, I., and Ozawa, S. 2007. Analysis of human interruptibility in the home environment. Proceedings of CHI 2007 (San Jose, CA, USA). ACM Press, New York, 2681-2686.

[12] Taylor, J.H., Brown, K.L., Toivenen, J., and Holah, J.T. 2000. A microbiological evaluation of warm air hand driers with respect to hand hygiene and the washroom environment. Journal of Applied Microbiology, 89(6), 910-919. 